\title{
Impact of age on clinical presentation, treatment, and cancer-specific survival of patients with small-cell carcinoma of the prostate
}

This article was published in the following Dove Press journal:

Clinical Interventions in Aging

9 July 2013

Number of times this article has been viewed

Jue Wang'

Fen Wei Wang ${ }^{2}$

'Department of Internal Medicine, Oncology-Hematology Division, University of Nebraska Medical Center, ${ }^{2}$ Department of Internal Medicine, Creighton University Medical School, Omaha, NE, USA
Correspondence: Jue Wang

Division of Oncology/Hematology,

Department of Internal Medicine,

University of Nebraska Medical Center,

Omaha, NE 68198-7680, USA

Tel +l 4025595520

Fax + I 4025596520

Email juewang@unmc.edu
Background: The effects of age on clinical presentation, treatment, and outcomes for patients with small-cell carcinoma of the prostate (SCCP) are unclear.

Methods: A retrospective review was performed on 259 patients who were identified with SCCP in the national Surveillance, Epidemiology, and End Results (SEER) registry from January 1973 to December 2004. The patients were categorized into two groups according to age at diagnosis, ie, younger than 75 years $(n=158,61 \%)$ or 75 years and older $(n=101,39 \%)$. Patient and treatment characteristics and cancer-specific survival were compared between the groups. Multivariate analysis was performed to identify independent prognostic factors associated with cancer-specific survival.

Results: The median age of the patients was 72 (30-95) years. There was no significant difference in terms of tumor characteristics, concomitant adenocarcinoma grade, SEER stage, and treatment (including prostatectomy and radiation therapy) received between the groups. Median cancer-specific survival was 19 months (95\% confidence interval 13-25). By multivariate Cox proportional hazard modeling, older age group (hazard ratio [HR] 1.95; $P=0.001$ ), concomitant high-grade adenocarcinoma (HR 7.13; $P=0.007$ ), and not having prostatectomy (HR 3.77; $P=0.005$ ) were found to be significant independent predictors of poor cancer-specific survival.

Conclusion: Older patients with SCCP had increased risk of poor cancer-specific survival. Whether this age-related poor outcome can be attributed to more aggressive tumor biology in older patients, or is simply a reflection of age-related poor performance status and suboptimal chemotherapy needs further investigation.

Keywords: small-cell carcinoma, prostate, radical prostatectomy, radiation, cancer-specific survival, age

\section{Introduction}

Prostate cancer is the most common malignancy in men in the US. ${ }^{1}$ The majority of prostate cancers are adenocarcinomas. With increasing life expectancy and wide adoption of prostate-specific antigen screening, an increasing number of elderly men are being diagnosed with prostate cancer. ${ }^{2}$ In addition to prostate-specific antigen and Gleason score, age is considered a key prognostic factor in therapeutic decisionmaking. ${ }^{3,4}$ Because of its indolent course and the fact that the majority of patients are diagnosed early, disease progression often occurs many years after the initial diagnosis. Elderly men who have concurrent severe comorbidities may not experience progression to metastatic disease during their lifetime. Although organ-confined disease can be cured by radical prostatectomy and local radiation therapy, conservative management, 
including active surveillance and watchful waiting of older men with early-stage disease, has been suggested as a viable option. ${ }^{4}$

Small-cell carcinoma of the prostate (SCCP) is an uncommon but aggressive subtype of prostate cancer. ${ }^{5-8}$ In contrast with adenocarcinoma of the prostate, current knowledge on SCCP is largely limited to retrospective case series and case reports. ${ }^{5-12}$ Clinically, SCCP may arise de novo and be identified at the time of initial diagnosis. However, more often, the small-cell component manifests itself late in the course of the disease. The clinical and pathologic features of $\mathrm{SCCP}^{5-8}$ differ from those of adenocarcinoma. SCCP-specific features include a predilection for visceral metastases, lytic bone involvement, a relatively low serum prostate-specific antigen concentration, resistance to androgen deprivation therapy, and a high response rate to cisplatin-etoposide chemotherapy. ${ }^{9-12}$

The elderly population in the US is growing at an unprecedented rate. Current projections suggest an increase in the number of individuals over the age of 65 years from 33.6 million (13\%) in 1990 to 70.2 million (20\%) by $2030 .{ }^{13}$ Current life expectancy for an individual reaching 70 years of age is 12.4 years for males and 15.7 years for females. ${ }^{14}$ Despite the high prevalence of prostate cancer in the elderly and the importance of decision-making regarding treatment, there is little information on the impact of age at clinical presentation, treatment decisions, and survival outcomes in patients with SCCP. To improve our understanding of this tumor, we have undertaken a comprehensive analysis of patients with SCCP identified in the National Cancer Institute Surveillance, Epidemiology, and End Results (SEER) database.

\section{Materials and methods Data source and study population}

Data for this study were obtained from SEER*Stat public use data files, available online at the National Cancer Institute website (http://seer.cancer.gov/registries/data.html). SEER currently consists of 17 statewide and regional tumor registries spread throughout the US, covering approximately $26 \%$ of the population. The individual registries are geographically located to oversample minority populations, including African-Americans, Hispanics, Asian Pacific Islanders, and Native Americans. ${ }^{15}$

\section{Variables}

SEER routinely collects data on patient demographics (age at diagnosis, year of diagnosis, race/ethnicity, marital status, and geographic residence at time of diagnosis), tumor characteristics (grade and stage), treatment (radical prostatectomy, radiation), and follow-up documentation of vital status and cause of death. ${ }^{15}$ Cases of SCCP were extracted from SEER on the basis of anatomic site (ICD-O-2 code C61.9) and histology type (ICD-O code 8041-45) for patients first diagnosed and/or treated between January 1973 and December 2004.

Pure small-cell carcinoma of the prostate is extremely rare. When it does occur, it is usually concomitant with prostatic adenocarcinoma. Grading information was available for concomitant prostatic adenocarcinoma. The Gleason grading scheme can be used for the glandular component, but not for the small-cell component of prostate cancer. ${ }^{16}$ The World Health Organization's standard grading system was used, with four separate categories (well, moderately well, poorly differentiated, and undifferentiated). We combined the undifferentiated carcinoma and poorly differentiated carcinoma grades into a single group (poorly/undifferentiated carcinoma) in the downstream subset analyses.

Tumor stage was evaluated by the SEER historic staging system (localized, regional, and distant). The SEER summary stage was produced using the extent of disease information from medical records and pathology reports reviewed at the time of diagnosis. ${ }^{16}$

Survival was defined as the time between cancer diagnosis and death or the last known date alive. Patients known to be alive at the last contact were censored. Cases identified at the time of autopsy or only by death certificate were excluded from survival analysis.

\section{Statistical analysis}

The patients were categorized into two groups, ie, aged younger than 75 years $(n=158,61 \%)$ or 75 years and older $(n=101,39 \%)$. Comparisons of patients, tumor characteristics, and treatment between the two patient groups were based on the $\chi^{2}$ test.

For the survival analysis, we excluded patients with multiple primaries and those who were diagnosed at autopsy or on the basis of death certificates only. Survival duration was measured by the Kaplan-Meier method and compared by the log rank test. Statistical independence between prognostic variables was evaluated by multivariate analysis using the Cox proportional hazard model. ${ }^{17,18}$

All statistical calculations were performed using Statistical Package for Social Sciences version 12.0 (Apache Software Foundation 2000, SPSS Inc, Chicago, IL, USA). Comparative differences were considered to be statistically significant at $P<0.05$. 


\section{Results}

\section{Incidence}

Of 629,338 patients with prostate cancer identified in the SEER 17 registries during the study period, 259 were found to have histologically confirmed SCCP, representing $0.04 \%$ of all patients with prostate cancer.

\section{Patient and tumor characteristics}

Table 1 summarizes the characteristics of the 259 patients with SCCP identified in the SEER database during the study period. Most of the patients $(85.3 \%)$ were white. The median age of the cohort was $72(30-95)$ years.

Of the 177 patients with known concomitant adenocarcinoma, 157 (88.7\%) were classified as having high-grade poorly/undifferentiated carcinoma. Of the 198 patients with staging information in the SEER registry,

Table I Characteristics of 259 patients with small-cell carcinoma of the prostate diagnosed between January 1973 and December 2004

\begin{tabular}{|c|c|c|c|c|}
\hline \multirow[t]{2}{*}{ Characteristics } & \multirow[t]{2}{*}{$\bar{n}$} & \multicolumn{2}{|c|}{ Age at diagnosis } & \multirow[t]{2}{*}{$P$} \\
\hline & & $<75$ years & $\geq 75$ years & \\
\hline \multicolumn{5}{|l|}{ Ethnicity } \\
\hline Black & 26 & 20 & 6 & 0.21 \\
\hline White & 221 & $|3|$ & 90 & \\
\hline Other & 12 & 7 & 5 & \\
\hline \multicolumn{5}{|l|}{ Married } \\
\hline Yes & 182 & 116 & 66 & $<0.0001$ \\
\hline No & 37 & 27 & 10 & \\
\hline Widower & 33 & 9 & 24 & \\
\hline Unknown & 7 & 6 & I & \\
\hline \multicolumn{5}{|l|}{ Grade } \\
\hline Well differentiated & 10 & 4 & 6 & 0.06 \\
\hline Moderately differentiated & 10 & 9 & I & \\
\hline Poorly differentiated & 60 & 40 & 20 & \\
\hline Undifferentiated & 97 & 62 & 35 & \\
\hline Unknown & 82 & 43 & 39 & \\
\hline \multicolumn{5}{|l|}{ SEER stage } \\
\hline Locoregional & 75 & 46 & 29 & 0.99 \\
\hline Distant & 123 & 74 & 49 & \\
\hline Unstaged & 18 & 11 & 7 & \\
\hline Unknown & 43 & 27 & 16 & \\
\hline \multicolumn{5}{|l|}{ Prostatectomy } \\
\hline Yes & 15 & 11 & 4 & 0.60 \\
\hline No & 218 & $|3|$ & 87 & \\
\hline Unknown & 26 & 16 & 10 & \\
\hline \multicolumn{5}{|l|}{ Radiation } \\
\hline Yes & 85 & 56 & 29 & 0.53 \\
\hline No & 169 & 99 & 70 & \\
\hline Unknown & 5 & 3 & 2 & \\
\hline \multicolumn{5}{|l|}{ Year of diagnosis } \\
\hline $1973-1989$ & 76 & 47 & 29 & 0.86 \\
\hline 1990-2004 & 183 & 111 & 72 & \\
\hline
\end{tabular}

Abbreviation: SEER, Surveillance, Epidemiology, and End Results.
$123(62.1 \%)$ were classified as having regional or distant stage disease (Table 1). Comparing patients aged $<75$ and those $\geq 75$ years, there was no significant difference in ethnicity, tumor characteristics (such as concomitant prostatic adenocarcinoma grade, SEER stage), or treatment (including prostatectomy and radiation therapy) received.

\section{Survival}

Overall, 230 of 259 (89\%) patients died of SCCP during the follow-up period. Figure 1A shows a Kaplan-Meier plot of overall survival in these patients. Median overall survival for all cases was 10 months $(95 \%$ confidence interval [CI] 8.2-11.7).

Cases identified at autopsy or on the basis of a death certificate alone were excluded from the cancer-specific survival analysis. In total, 218 patients were included in this analysis. Figure 1B shows the Kaplan-Meier plots of cancer-specific survival, the median of which was 19 months (95\% CI 13.4-24.6).

There was a significant difference in cancer-specific survival rates between patients with concomitant lowgrade and high-grade prostatic adenocarcinoma $(P<0.01$, Figure 1C), patients with locoregional and distant disease $(P=0.005$, Figure 1D), and those aged younger than 75 years and 75 years or older $(P=0.005$, Figure $1 \mathrm{E})$. The median cancer-specific survival for those aged younger than 75 years and 75 years or older was 26 months (95\% CI 13-39) and 15 months (95\% CI 7.8-22.2), respectively.

Table 2 shows the results of multivariate survival analysis by Cox proportional hazard modeling. Older age at diagnosis (hazard ratio [HR] 1.95; $P=0.001$ ), concomitant high-grade adenocarcinoma (HR 7. 13; $P=0.007$ ), and not having prostatectomy (HR 3.77; $P=0.005$ ) were found to be significant independent predictors of poor cancer-specific survival.

\section{Discussion}

The incidence of prostate cancer is known to increase with advancing age, ${ }^{1,17}$ and SCCP is no exception. In this study, $73.7 \%$ of patients with SCCP were diagnosed when they were over the age of 65 years, and about $39 \%$ were aged over 75 years. The incidence of small-cell carcinoma in clinical specimens is estimated to be $0.5 \%-2 \%,{ }^{2-5}$ and autopsy studies have reported that small-cell carcinoma occurs in $10 \%-20 \%$ of conventionally treated adenocarcinoma of the prostate. ${ }^{19}$ In our study, SCCP accounted for approximately $0.04 \%$ of primary prostate cancers during the study period, which is lower than that reported in the abovementioned 

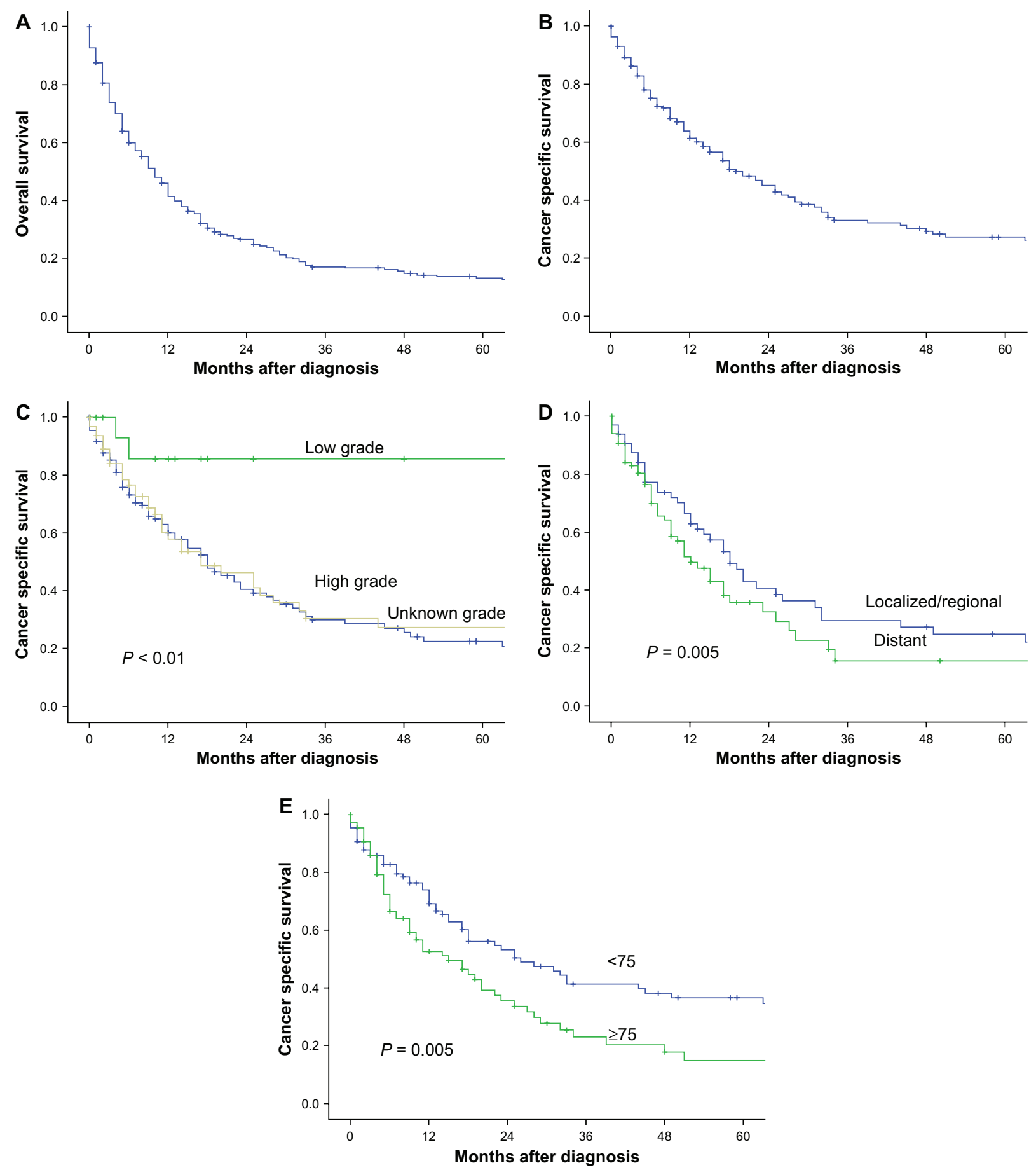

Figure I (A) Kaplan-Meier curve for overall survival (OS) in the entire cohort of patients with small-cell carcinoma of the prostate (SCCP) ( $\mathrm{n}=259)$. (B) cancer-specific survival of patients with SCCP. (C) cancer-specific survival of patients with SCCP by tumor histological grade. (D) cancer-specific survival of patients with SCCP by tumor stage. (E) cancer-specific survival of patients with SCCP by age group.

Notes: For the cancer-specific survival analyses, we excluded cases identified at autopsy or on the basis of death certificates only, and those with multiple primaries. A total of 218 patients were included in the cancer-specific survival analysis. The $P$ value is shown for the log-rank test between variables.

single-center studies. There are several possible explanations for the large discrepancy in these figures.

First, patients with a rare subtype of prostate cancer tend to visit referral centers for a second opinion. Second, the data source also likely contributed to the different incidence rates between the single-institution studies and our population study. SEER routinely collects histological data at the time of initial diagnosis, and additional pathological diagnoses from subsequent biopsies are not included. Finally, SCCP may arise de novo and be identified at the time of initial diagnosis. 
Table 2 Cox proportional multivariate analysis of factors associated with cancer-specific mortality in 218 patients with small-cell carcinoma of the prostate

\begin{tabular}{|c|c|c|c|c|}
\hline Characteristics & Group & HR & $95 \% \mathrm{Cl}$ & $P$ value \\
\hline Age at diagnosis & $<75$ & 1.00 & & \\
\hline (years) & $\geq 75$ & 1.95 & $(1.30-2.93)$ & 0.001 \\
\hline \multirow[t]{3}{*}{ Ethnicity } & White & 1.00 & & \\
\hline & Black & 1.11 & $(0.59-2.07)$ & 0.747 \\
\hline & Other & 1.68 & $(0.83-3.38)$ & 0.147 \\
\hline \multirow[t]{3}{*}{ Grade } & Low & 1.00 & & \\
\hline & High & 7.13 & $(1.70-29.9)$ & 0.007 \\
\hline & Unknown & 6.51 & (1.52-27.9) & 0.012 \\
\hline \multirow[t]{4}{*}{ SEER stage } & Locoregional & 1.00 & & \\
\hline & Distant & 0.95 & $(0.59-1.53)$ & 0.832 \\
\hline & Unstaged & 0.79 & $(0.3 \mathrm{I}-2.06)$ & 0.634 \\
\hline & Unknown & 0.53 & $(0.26-1.14)$ & 0.066 \\
\hline \multirow[t]{3}{*}{ Marital status } & Yes & & & \\
\hline & No & 1.12 & $(0.74-1.69)$ & 0.606 \\
\hline & Unknown & 0.87 & $(0.63-1.5 I)$ & 0.799 \\
\hline \multirow[t]{2}{*}{ Year of diagnosis } & 1973-1989 & 1.00 & & \\
\hline & 1990-2004 & 1.89 & $(0.63-1.57)$ & 0.893 \\
\hline \multirow[t]{3}{*}{ Prostatectomy } & Yes & 1.00 & & \\
\hline & No & 3.77 & $(1.5 \mathrm{I}-9.47)$ & 0.005 \\
\hline & Unknown & 2.36 & $(0.75-7.47)$ & 0.144 \\
\hline \multirow[t]{3}{*}{ Radiation } & Yes & 1.00 & & \\
\hline & No & 1.42 & $(0.93-2.5 \mathrm{I})$ & 0.105 \\
\hline & Unknown & 1.70 & $(0.32-3.63)$ & 0.911 \\
\hline
\end{tabular}

Abbreviations: HR, hazard ratio; $\mathrm{Cl}$, confidence interval; SEER, Surveillance, Epidemiology, and End Results.

More often, the small-cell component manifests itself late in the disease course in patients with metastatic prostate cancer, who suddenly develop widespread metastases in unusual locations, such as the liver, without an accompanying rise in serum prostate-specific antigen. ${ }^{19,20}$ In current clinical practice, rebiopsies are seldom performed in patients with prostate cancer because of the perception that rebiopsy of these patients in the face of known prostate cancer is not warranted, especially in elderly patients with advanced disease. Therefore, the incidence of small-cell carcinoma and the clinical impact of this subtype of prostate cancer in elderly men is likely underestimated and under-reported. ${ }^{21-24}$

Controversy exists regarding the importance of patient age in the behavior of prostate cancer. ${ }^{25-29}$ Contrary to the common belief that elderly men with prostate cancer will die of something else, a recent study demonstrated that men age 75 years and older are more likely to be diagnosed with late-stage and more aggressive prostate cancer and therefore die from the disease more often than younger men. ${ }^{30}$ Older men have largely been excluded from clinical trials of the benefits of early detection, based on the idea that older men would not benefit from early detection because of their shorter remaining life expectancy. ${ }^{31,32}$
Age has also been shown to affect the treatments offered to patients with prostate cancer. A retrospective study of 260,000 patients from the National Cancer Database treated from 1992 to 1994 confirmed that older patients with prostate cancer are often treated less aggressively. ${ }^{33}$ In another large retrospective study using the Cancer of the Prostate Strategic Urologic Research Endeavor database, $26 \%$ of men aged $\geq 75$ years presented with high-risk disease (Cancer of the Prostate Risk Assessment score 6-10). Older men were more likely to receive less aggressive therapy. Controlling for age, comorbidity, and risk, older men with high-risk tumors receiving local therapy had a $46 \%$ reduction in mortality compared with those treated conservatively. ${ }^{34}$ The current management of prostate cancer does not reflect recent data with respect to elderly patients and the benefits they might gain from increased therapeutic intervention.

There is little information regarding the impact of age on clinical presentation, treatment, or survival outcomes in patients with SCCP. In our study, there was no significant difference in terms of tumor characteristics, such as concomitant prostatic adenocarcinoma grade, SEER stage, and treatment (including prostatectomy and radiation therapy) received between men aged younger than 75 years and those aged 75 years or older. However, compared with their younger counterparts, older patients with SCCP had a two-fold higher risk of dying from their prostate cancer. Our study is consistent with the previous finding that older age is an independently poor prognostic factor in patients with SCCP. ${ }^{35}$ Further research is needed to clarify whether this age-related poor outcome is simply the consequence of comorbid conditions, suboptimal chemotherapy, treatmentrelated side effects with advancing age, or the results of age-specific differences in tumor biology and dysregulation of the oncogenic pathway. ${ }^{36,37}$ Although host-related factors, such as comorbid conditions, play an important role in the prognosis of the elderly with cancer, a large-scale genomic analysis $^{36}$ dissecting the biology of acute myelogenous leukemia as a function of age with regard to underlying molecular events, demonstrated that acute myelogenous leukemia arising in the elderly is a unique biological entity driven by unifying oncogenic signaling pathways. With our aging population, it is important to understand the age-related differential biological behavior of tumors. Our study should raise awareness that older men are actually having worse outcomes from SCCP, and help doctors and patients embarking on discussions about the benefits and risks of treatment. 
This research should be interpreted in light of some limitations, including its retrospective design. Our data did not allow us to examine any chemotherapy given, patient performance status, or comorbidities, all of which may influence survival in patients with cancer. Unlike singlecenter studies, the accuracy of staging and pathological diagnosis within a national registry may vary widely across institutions. We did make an effort to overcome this limitation by measuring prostate cancer-specific survival rather than overall survival. The strengths of this study include its population-based design and the large sample size included, with the latter being of particular importance for analysis of rare tumors such as pure SCCP.

\section{Conclusion}

Advanced age, high-grade concomitant prostatic adenocarcinoma, and not having radical prostatectomy were independent predictors of poor survival. Whether the poor agerelated outcome can be attributed to age-specific dysregulation in the oncogenic pathway or is simply the consequences of poor performance status and suboptimal chemotherapy on the basis of age needs further investigation.

\section{Acknowledgments}

The authors acknowledge the efforts of the Applied Research Branch in the Division of Cancer Prevention and Population Science of the National Cancer Institute and the SEER registries in providing data for this study. Interpretation and reporting of these data were solely the responsibility of the authors.

\section{Disclosure}

The authors report no conflicts of interest in this work.

\section{References}

1. Crawford ED. Epidemiology of prostate cancer. Urology. 2003; 62(6 Suppl 1):3-12.

2. Scher HI, Isaacs JT, Zelefsky MJ, et al. Prostate cancer. In: Abeloff MD, Armitage JO, Lichter AS, et al, editors. Clinical Oncology, 2nd ed. New York, NY: Churchill Livingstone; 2000.

3. Bechis SK, Carroll PR, Cooperberg MR. Impact of age at diagnosis on prostate cancer treatment and survival. J Clin Oncol. 2011;29: 235-241.

4. Chodak GW, Thisted RA, Gerber GS, et al. Results of conservative management of clinically localized prostate cancer. $N$ Engl J Med. 1994;33:242-248.

5. Tetu B, Ro JY, Ayala AG, et al. Small cell carcinoma of the prostate: Part 1 - A clinicopathologic study of 20 cases. Cancer. 1987;59: 1803-1809.

6. Ro JY, Têtu B, Ayala AG, Ordóñez NG. Small cell carcinoma of the prostate. II. Immunohistochemical and electron microscopic studies of 18 cases. Cancer. 1987;59:977-982.
7. Pearse AG, Takor T. Embryology of the diffuse neuroendocrine system and its relationship to the common peptides. Fed Proc. 1979;38: 2288-2294.

8. Amato RJ, Logothetis CJ, Hallinan R, et al. Chemotherapy for small cell carcinoma of prostatic origin. J Urol. 1992;147:935-937.

9. Oesterling JE, Hauzeur CG, Farrow GM. Small cell anaplastic carcinoma of the prostate: a clinical, pathological and immunohistological study of 27 patients. $J$ Urol. 1992;147:804-807.

10. Wang W, Epstein JI. Small cell carcinoma of the prostate. A morphologic and immunohistochemical study of 95 cases. Am J Surg Pathol. 2008;32:65-71.

11. Helpap B, Köllermann J, Oehler U. Neuroendocrine differentiation in prostatic carcinomas: histogenesis, biology, clinical relevance, and future therapeutical perspectives. Urol Int. 1999;62:133-138.

12. Bonkhoff H, Remberger K. Differentiation pathways and histogenetic aspects of normal and abnormal prostatic growth: a stem cell model. Prostate. 1996;28:98-106.

13. Yancik R. Cancer burden in the aged: an epidemiologic and demographic overview. Cancer. 1997;80:1273-1283.

14. Walter LC, Covinsky KE. Cancer screening in elderly patients. A framework for individualized decision making. JAMA. 2001;285: 2750-2756.

15. Surveillance, Epidemiology, and End Results (SEER) Program. PublicUse Data (1973-2004), National Cancer Institute, DCCPS, Surveillance Research Program, Cancer Statistics Branch, released April 2002, based on the November 2006 submission. Available from: http://www.seer. cancer.gov/about/expansion.html. Accessed Nov 29, 2008.

16. Gleason DF. Classification of prostatic carcinomas. Cancer Chemother Rep. 1966;50:125-128.

17. Kaplan EL, Meier P. Nonparametric estimation from incomplete observations. J Am Stat Assoc. 1958;53:457-481.

18. Cox DR. Regression models and life-tables. J Royal Stat Soc B. $1972 ; 34: 187-220$

19. Turbat-Herrera EA, Herrera GA, Gore I, et al. Neuroendocrine differentiation in prostatic carcinomas. A retrospective autopsy study. Arch Pathol Lab Med. 1988;112:1100-1105.

20. Yashi M, Ishikawa S, Ochi M, et al. Small cell/neuroendocrine carcinoma may be a more common phenotype in advanced prostate cancer. Urol Int. 2002;69:166-168.

21. Nadig SN, Deibler AR, El Salamony TM, et al. Small cell carcinoma of the prostate: an underrecognized entity. Can J Urol. 2001;8:1207-1210.

22. Miyoshi Y, Uemura H, Kitami K, et al. Neuroendocrine differentiated small cell carcinoma presenting as recurrent prostate cancer after androgen deprivation therapy. BJU Int. 2001;88:982-983.

23. Palmgren JS, Karavadia SS, Wakefield MR. Unusual and underappreciated: small cell carcinoma of the prostate. Semin Oncol. 2007;34:22-29.

24. Yashi M, Ishikawa S, Ochi M, Tokue A. Small cell/neuroendocrine carcinoma may be a more common phenotype in advanced prostate cancer. Urol Int. 2002;69:166-168.

25. Austin JP, Convery K. Age race interaction in prostatic adenocarcinoma treated with external beam irradiation. Am J Clin Oncol. 1993;16: $140-145$.

26. Gronberg H, Damber JE, Jonsson H, Lenner P. Patient age as a prognostic factor in prostate cancer. J Urol. 1994;152:892-895.

27. Herold DM, Hanlon AL, Movsas B, Hanks GE. Age-related prostate cancer metastases. Urology. 1998;51:985-990.

28. Obek C, Lai S, Sadek S, Civantos F, Soloway MS. Age as a prognostic factor for disease recurrence after radical prostatectomy. Urology. 1999;54:533-538.

29. Freedland SJ, Presti JC, Kane CJ, et al. Do younger men have better biochemical outcomes after radical prostatectomy? Urology. 2004;63: 518-522.

30. Scosyrev E, Messing EM, Mohile S, Golijanin D, Wu G. Prostate cancer in the elderly: frequency of advanced disease at presentation and disease-specific mortality. Cancer. 2012;118:3062-3070. 
31. Schröder FH, Hugosson J, Roobol MJ, et al; ERSPC Investigators. Prostate-cancer mortality at 11 years of follow-up. $N$ Engl J Med. 2012;366:981-990.

32. Andriole GL, Crawford ED, Grubb RL 3rd, et al; PLCO Project Team. Prostate cancer screening in the randomized Prostate, Lung, Colorectal, and Ovarian Cancer Screening Trial: mortality results after 13 years of follow-up. J Natl Cancer Inst. 2012;104:125-132.

33. Mettlin CJ, Murphy GP, Cunningham MP, Menck HR. The National Cancer Data Base report on race, age, and region variations in prostate cancer treatment. Cancer. 1997;80:1261-1266.

34. Bechis SK, Carroll PR, Cooperberg MR. Impact of age at diagnosis on prostate cancer treatment and survival. J Clin Oncol. 2011;29: 235-241.
35. Deorah S, Rao MB, Raman R, Gaitonde K, Donovan JF. Survival of patients with small cell carcinoma of the prostate during 1973-2003: a population-based study. BJU Int. 2012;109:824-830.

36. Rao AV, Valk PJ, Metzeler KH, et al. Age-specific differences in oncogenic pathway dysregulation and anthracycline sensitivity in patients with acute myeloid leukemia. J Clin Oncol. 2009;27:5580-5586.

37. Mostertz W, Stevenson M, Acharya C, et al. Age- and sex-specific genomic profiles in non-small cell lung cancer. JAMA. 2010;303: $535-543$.
Clinical Interventions in Aging

\section{Publish your work in this journal}

Clinical Interventions in Aging is an international, peer-reviewed journal focusing on evidence-based reports on the value or lack thereof of treatments intended to prevent or delay the onset of maladaptive correlates of aging in human beings. This journal is indexed on PubMed Central, MedLine, the American Chemical Society's 'Chemical Abstracts

\section{Dovepress}

Service' (CAS), Scopus and the Elsevier Bibliographic databases. The manuscript management system is completely online and includes a very quick and fair peer-review system, which is all easy to use. Visit http://www.dovepress.com/testimonials.php to read real quotes from published authors.

Submit your manuscript here: http://www.dovepress.com/clinical-interventions-in-aging-journal 